\title{
Population-Based Case-Control Study of Occupational Exposure to Electromagnetic Fields and Breast Cancer
}

\author{
EDWIN VAN WIJNGAARDEN, MSc, LEENA A. NYLANDER-FRENCH, PrD, $\mathrm{CIH}$, \\ ROBERT C. MILLIKAN, PHD, DAVID A. SAVITZ, PHD, AND DANA LOOMIS, PHD
}

\begin{abstract}
PURPOSE: This population-based case-control study examined occupational exposure to electromagnetic fields in relation to female breast cancer incidence among 843 breast cancer cases and 773 controls. METHODS: Exposure was classified based on work in the two longest-held jobs, and indices of curnulative exposure to magnetic fields based on a measurement survey.

RESULTS: Female breast cancer was not associated with employment as an office or industrial worker. For the total study population, cumulative exposure over the entire career, and in the past 0-10 and 10-20 years generally showed odds ratios (ORs) close to the null. Moderately elevated risks were found for intermediate but not high levels of cumulative exposure accumulated 20 or more years ago $(O R=1.5 ; 95 \% \mathrm{CI}=$ $1.1-2.0)$. Associations were stronger for premenopausal wornen $(\mathrm{OR}=1.7 ; 95 \% \mathrm{Cl}=1.1-2.7)$ in the past $10-20$ years, and those with estrogen-receptor positive $(E R+)$ breast tumors $(\mathrm{OR}=2.06 ; 95 \% \mathrm{CI}=1.1-$ 4.0). No consistent dose-response patterns were observed.

CONCLUSIONS: These findings give little support to the hypothesis that electromagnetic fields cause cancer of the female breast.

Ann Epidemiol 2001;11:297-303. 2001 Elsevier Science Inc. All rights reserved.
\end{abstract}

KEY worDst Electromagnetic Fields, Female Breast Cancer, Case-Control Studies, North Carolina.

\section{INTRODUCTION}

Breast cancer is the third most common cancer overall in the world, and accounts for an estimated $21 \%$ of total cancer among women (1). The etiology of breast cancer remains poorly understood (2).

The melatonin hypothesis, first postulated by Stevens (3), proposes a very specific and testable mechanism link. ing extremely low-frequency electromagnetic fields (EMFs) and breast cancer: exposure to electromagnetic fields or light-at-night decreases blood levels of melatonin, a hormone produced by the pineal gland that is thought to inhibit mammary carcinogenesis (4). Support for this hypothesis was found in pinealectomy and constant-light studies, which indicate that eliminating the endogenous nocturnal melatonin signal enhances mammary tumorigenesis in fernale rats (5). Some studies have suggested inhibition of melatonin production in humans mediated by EMF exposure (6-11), while others have not (12-16).

From the Departments of Epidemiology (E.v.W., R.C.M., D.A.S., D.L.) and Environmental Sciences and Engineering (L.A.N.-F.), School of Pub. lic Health, University of North Carolina at Chapel Hill, Chapel Hill, NC

Address correspondences to: Leena A. Nylander-French, $\mathrm{PhD}, \mathrm{Cl}$ Department of Environmental Sciences and Engineering, CB 7400 , School of Public Health, University of North Carolinn at Chapel Hill, Chapel Hill, NC 27599.7400

Received August 3, 200; revised November 20, 2000; accepted November 29,2000 .
We conducted a population-based case-control study to consider the risk of female breast cancer among 843 breast cancer cases and 773 controls in 24 counties in central and eastern North Carolina for whom individual estimates of occupational exposure to magnetic fields were obtained based on the longest and second-longest held occupation. We considered time windows to address possible latency effects of exposure, and effect modification by menopausal and estrogen-receptor status to evaluate possible etiologic heterogeneity $(17,18)$.

\section{METHODS}

\section{Design and Study Population}

Details of the study design and identification and characteristics of cases and controls in the first phase of the Carolina Breast Cancer Study (CBCS) have been published in detail elsewhere $(19,20)$ and are briefly described here. The $\mathrm{CBCS}$ is an ongoing population-based case-control study to identify genetic and environmental risk factors among Caucasian and African-American residents of 24 counties in central and eastern North Carolina. Eligible cases were identified through the North Carolina Central Cancer Registry, and included women aged $20-74$ years diagnosed with invasive breast cancer for the first time from May 1, 1993, through September 30, 1995. From all eligible 


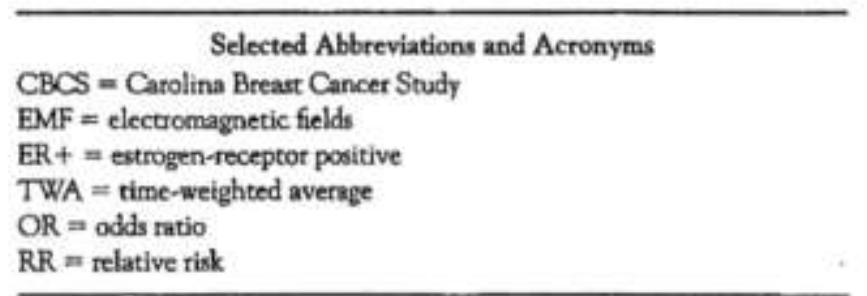

cases, sampling took place to insure adequate representation of four subgroups (younger and older Black women, and younger and older non-Black women) thereby providing equal sample sizes in the groups. Controls were sampled from lists of the Division of Motor Vehicles for women under age 65 and Health Care Financing Administration for women age 65 and over, using a modification of randomized recruitment $(21,22)$. Sampling fractions were designed to insure frequency matching to cases by race and five-year age group as well as adequate numbers after exclusion because of ineligibility, inability to contact, or refusal to participate (19).

During Phase I of the CBCS, 861 cases and 790 controls were identified (23). For the present analysis, eligible study participants were those who reported both a longest held job that could be categorized in one of six a priori occupational categories (see below) and information on duration of employment in that job. Accordingly, 35 of 1651 study participants were excluded from further analyses: 27 women were never employed for 6 months or more in one job, 3 women were working only as volunteers, 1 woman was a housewife, 1 wornan did not report the duration of employment in the job held longest, and for 3 women the longest held job was unknown. Therefore, 843 cases and 773 controls were available for analysis.

\section{Assignment of Exposure to Magnetic Fields}

Occupational exposure to magnetic fields was estimated, focusing on the time-weighted average (TWA) (24). A convenience sample consisting of 800 participants who had not been asked previously about occupational or environmental exposures as part of previous epidemiological studies of this study population were identified. Women over the age of $65(n=190)$ were excluded from the measurement survey. A total of 273 women (45\%) who agreed to participate was monitored by recording their TWA using a personal average magnetic field exposure meter (AMEX 3-D, Enertech Consultants, Campbell, CA). Two hundred two women provided usable measurements; 136 women provided two magnetic field measurements, while 66 women provided only one measurement. A total of 217 measurements was used to compute TWA exposures and arithmetic means across occupational categories considered in this study (24).

A homemaker category and six a priori occupational categories were constructed based on occupations coded according to the system used in the 1980 U.S. Census of Population (U.S. Bureau of the Census), with consideration of work tasks and exposure potential: office workers, nurses and health technicians, industrial workers, computer programmers and technicians, teachers and school adminis. trators, and miscellaneous workers. The miscellaneous group was formed to classify jobs that did not fall into one of the other categories. Table 1 presents the arithmetic mean magnetic field exposure across occupational categories.

Individual exposure assignment was based on the longest and second-longest held job, and the number of years and hours per workweek employed in the specific jobs reported by the study participants in those jobs. If no second-longest held job was reported, then cumulative exposure indices were based only on the longest-held job. If the number of hours per workweek employed was not reported, a 40-hour workweek was assumed. For the longest held and second-longest held job separately, the average job group' exposure was summed by the number of years the individual was employed in a specific time interval, and multiplied by the proportion of all hours spent at work ( 50 weeks $\times$ hours per work week divided by 52 weeks $\times 168$ hours per week) to yield $\mu \mathrm{T}$-years of occupational exposure. Total cumulative exposure in a specific time interval was determined by summing occupational exposure based on the two longest held jobs.

TABLE 1. Average magnetic field exposure and duration of employment in six a prioti occupational categories: Carolina Breast Cancer Study

\begin{tabular}{|c|c|c|c|c|}
\hline \multirow[b]{2}{*}{ Occupational Category } & \multicolumn{2}{|c|}{ Magnetic field exposure $(\mu T)$} & \multicolumn{2}{|c|}{$\begin{array}{l}\text { Duration of work } \\
\text { (years) for longest held job }\end{array}$} \\
\hline & $\begin{array}{c}\text { Number of } \\
\text { measurements }\end{array}$ & $\mathrm{AM}(\mathrm{SD}) *$ & $\begin{array}{c}\text { Number of } \\
\text { workers }\end{array}$ & $\mathrm{AM}(\mathrm{SD})$ \\
\hline Office workers & 94 & $0.18(0.18)$ & 548 & $15.1(9.3)$ \\
\hline Nurses and health technicians & 22 & $0.15(0.06)$ & 175 & $17.9(9.5)$ \\
\hline Industrial workers & 9 & $0.54(0.90)$ & 259 & $15.3(8.7)$ \\
\hline Computer programmers and technicians & 14 & $0.17(0.10)$ & 42 & $13.8(8.3)$ \\
\hline Teachers snd school administratons & 43 & $0.13(0.10)$ & 168 & $17.2(9.6)$ \\
\hline Miscellaneous & 35 & $0.23(0.16)$ & 424 & $17.1(12.0)$ \\
\hline Total & 217 & $0.19(0.24)$ & 1616 & $16.1(10.1)$ \\
\hline
\end{tabular}

AM, arithmetic mean; $S D$, standard deviation. 


\section{Confounding Factors and Effect Modifiers}

Age and race (Black, non-Black) were part of the case and control selection procedure (19), and were adjusted for in the analyses. Information on other potential confounders and effect modifiers was obtained from questionnaires. The following confounders were considered based on previous literature and analyses of this population: first degree family history of breast cancer, educational status $(<9$ years, 9 years-high school graduate, $>$ high school), number of fullterm pregnancies $(0,1, \geqslant 2)$, geographic area $(<50,000$ and $\geqslant 50,000$ residents), smoking status (never, former, current), alcohol use (ever, never), use of oral contraceptives (ever, never), any hormone replacement therapy (never, ever), and body mass index $(<25, \geqslant 25-<30$, $\geqslant$ $30 \mathrm{~kg} / \mathrm{m}^{2}$ ). Furthermore, menopausal and estrogen-receptor status were considered. For women under age 50, postmenopausal status was assigned to women who had undergone natural menopause, bilateral oophorectomy, or irradiation to the ovaries. In women age 50 or older, menopausal status was assigned on the basis of cessation of menstruation. Information on estrogen-receptor status was obtained for about $92 \%$ of the eligible cases.

\section{Statistical Analysis}

The association of breast cancer with exposure to magnetic fields was initially examined using occupational categories. Breast cancer risks were considered for office workers and industrial workers, two common occupations in this study population. An increased risk of breast cancer among office workers, a majority of whom may routinely use equipment such as photocopiers that produce extremely low-frequency EMFs, has been shown previously (25), whereas industrial workers are potentially exposed to high levels of magnetic fields. Risk estimates were calculated by duration of employment in the occupational category longest held; wornen employed in a specific occupational category for $>0-10$ years, $>10-20$ years, and $>20$ years were compared to women never employed in the category of interest.

In addition to the analyses of occupational categories, risk estimates were based on time-integrated exposure in specific time intervals: Based on the two longest held jobs, total exposure was assessed as cumulative exposure up the time of diagnosis for cases, or time of selection for controls. Furthermore, cumulative exposure was examined in three time intervals: past $0-10$ years, past $10-20$ years, and $>20$ years before diagnosis or selection. The time windows were chosen to consider possible latency of the effect of magnetic field exposure on breast cancer, and to evaluate the hypothesis that magnetic field exposure has a tumor promoting effect $(26,27)$.

For all time periods, exposure categories were created based on percentiles of exposure among controls. For total exposure, the referent category was equal to or below the
30 th percentile, with cut-points at the $>30-50,>50-70,>$ $70-90$, and $>90$ percentiles. For the $0-10$ and $>10-20$ year time intervals, the reference category was the absence of occupational exposure within the interval, with categories of $>0-30,>30-<60,60-<80$, and $>80$ percentiles. For exposure with a lag of 20 or more years, the reference category was the absence of occupational exposure within the lag period, with exposed categories of $>0-50,>50-80$, and $80+$ percentiles. The cut-points were chosen to ensure a reasonable variation in cumulative exposure in the statistical analysis, with a focus on high exposures.

Odds ratios (ORs) adjusted for age and race, and 95\% confidence intervals $(95 \% \mathrm{Cls}$ ) were derived from unconditional logistic regression models with the GENMOD procedure with SAS system software PC version 6.12 (SAS Institute, Cary, NC). Offset terms were incorporated into the logistic models in onder to control for the different ageand race-specific sampling fractions utilized for cases and controls $(19,21,22)$. The analysis of breast cancer risk in relation to duration of employment and cumulative indices of exposure was stratified by menopausal status to evaluate effect measure modification. The cases were divided by estrogen-receptor status to evaluate etiologic heterogeneity.

\section{RESULTS}

Fifty-two percent of all cases and 45 percent of controls were premenopausal. Fifty-eight percent of the cases with information on estrogen-receptor status were estrogenreceptor positive $(E R+)$. The average duration of employment in the longest held job was 16.1 years with a standard deviation (SD) of 10.1. Among the six occupational categories of interest, the longest duration of work in the job held longest was found for nurses and health technicians, whereas women employed as computer programmers and technicians had the shortest duration of employment ( $\mathrm{Ta}$ ble 1). About $67 \%$ of the women also reported a job second-longest held, with an average duration of 5.5 years $(\mathrm{SD}=$ 4.7) (data not shown). The total average duration of employment based on the two jobs combined was 19.8 years $(\mathrm{SD}=11.4)$.

Associations with traditional breast cancer risk factors were previously reported $(20)$. Restricting the analysis to the 1518 study participants who did not have missing data for any of the covariates of interest revealed little confounding of the ORs by the potential confounding factors, so the results reported here were based on all 1616 study participants, adjusted only for race and age.

Table 2 shows the risk of breast cancer by duration of employment as an office worker or industrial worker. There was no evidence for an increased risk of breast cancer with either type of work, with ORs varying from slightly below to slightly above unity. Similar results were observed with 
TABLE 2. Adjusted logistic regression odds ratios and 95 percent confidence levels for breast cancer relative to duration of work in selected occupations: Carolina Breast Cancer Study

\begin{tabular}{lrrl}
\hline Duration of employment (years) & Controls & Cases & OR $(95 \% \mathrm{Cl})$ \\
\hline Office-Workers & & & \\
0 & 504 & 564 & 1.0 \\
$>0-10$ & 80 & 84 & $0.7(0.5-1.0)$ \\
$>10-20$ & 102 & 126 & $1.1(0.8-1.4)$ \\
$20+$ & 87 & 69 & $0.8(0.6-1.1)$ \\
Industrial Workers & & & \\
0 & 643 & 714 & 1.0 \\
$>0-10$ & 35 & 38 & $0.9(0.6-1.5)$ \\
$>10-20$ & 55 & 50 & $0.9(0.6-1.4)$ \\
$20+$ & 40 & 41 & $1.1(0.7-1.7)$ \\
\hline
\end{tabular}

Adjusted for the effects of race (Black, non-Black) and age.

* OR, odds matio; $\mathrm{Cl}$, confidence interval.

stratification by menopausal status only (data not shown). Additional stratification by estrogen-receptor status sug. gested an increased risk of breast cancer with duration of employment as industrial worker among premenopausal women with ER + breast cancer cells, with odds ratios of $1.1(95 \% \mathrm{Cl}=0.5-2.5), 1.5(95 \% \mathrm{Cl}=0.8-3.1)$, and 1.8 $(95 \% \mathrm{Cl}=0.7-4.7)$ for $>0-10,>10-20$, and $20+$ years of employment, respectively. Risk estimates, however, were highly imprecise.

Table 3 shows the relative risk estimates for breast can. cer among the entire study population in relation to cumu- lative exposure to magnetic fields in several time intervals, and stratified by menopausal status. No clear dose-response relation between breast cancer risk and cumulative magnetic field exposure was observed. For the total study population, cumulative exposure over the entire career, and in the past $0-10$ and $10-20$ years generally showed ORs close to the null. Somewhat elevated risks were found for intermediate exposure levels accumulated 20 or more years ago, but not for the highest exposure level. For premenopausal women, the referent category is at somewhat lower risk in the past 10-20 years, with all exposed groups at similar risk. Similar results were observed with additional stratification by estrogen-receptor status (Table 4), although associations were somewhat stronger for premenopausal women with ER + status compared to other groups.

\section{DISCUSSION}

The results of this study give little support to the hypothesis that exposure to EMFs causes cancer of the female breast. Breast cancer was not associated with duration of employ. ment in office or industrial work environments with the possible exception for premenopausal women with ER+ breast cancer cells. Dose-response gradients in relation to cumulative indices of occupational magnetic field exposure were not observed, although sporadic indications of in-

TABLE 3. Adjusted logistic regression odds natios and 95 percent confidence levels for breast cancer relative to cumulative exposure to magnetic fields: Carolina Breast Cancer Study

\begin{tabular}{|c|c|c|c|c|c|c|c|}
\hline \multirow{2}{*}{$\begin{array}{l}\text { Exposure level } \\
\text { ( } \mu \mathrm{T} \text {-years) }\end{array}$} & \multirow{2}{*}{$\frac{\text { Total }}{\text { OR }(95 \% \mathrm{CI})^{*}}$} & \multicolumn{3}{|c|}{ Premenopausal } & \multicolumn{3}{|c|}{ Postmenopausal } \\
\hline & & Controls & Cases & OR $(95 \% \mathrm{CI})$ & Controls & Cases & OR $(95 \% \mathrm{Cl})$ \\
\hline \multicolumn{8}{|l|}{ Total exposure } \\
\hline 0.0 .59 & 1.0 & 145 & 177 & 1.0 & 86 & 87 & 1.0 \\
\hline$>0.59-0.90$ & $1.4(1.1-1.8)$ & 70 & 124 & $1.6(1.1-2.4)$ & 86 & 83 & $1.0(0.6-1.5)$ \\
\hline$>0.90-1.27$ & $1.1(0.8-1.5)$ & 79 & 76 & $0.9(0.6-1.3)$ & 74 & 77 & $1.1(0.7-1.7)$ \\
\hline$>1.27-2.43$ & $1.0(0.8-1.4)$ & 37 & 44 & $1.2(0.7-2.0)$ & 119 & 96 & $0.8(0.6-1.3)$ \\
\hline$>2.43$ & $1.2(0.8-1.7)$ & 16 & 18 & $1.1(0.5-2.2)$ & 61 & 61 & $1.0(0.6-1.7)$ \\
\hline \multicolumn{8}{|l|}{$0-10$ years } \\
\hline 0 & 1.0 & 33 & 33 & 1.0 & 138 & 141 & 1.0 \\
\hline$>0-0.12$ & $1.2(0.8-1.8)$ & 24 & 43 & $1.7(0.9-3.4)$ & 35 & 34 & $1.0(0.6-1.7)$ \\
\hline$>0.12-0.35$ & $1.0(0.7-1.3)$ & 114 & 154 & $1.3(0.7-2.2)$ & 120 & 101 & $0.8(0.6-1.2)$ \\
\hline$>0.35-0.47$ & $1.0(0.7-1.3)$ & 89 & 101 & $1.1(0.6-1.9)$ & 69 & 62 & $0.8(0.5-1.3)$ \\
\hline$>0.47$ & $1.1(0.8-1.6)$ & 87 & 108 & $1.3(0.7-2.3)$ & 64 & 66 & $1.0(0.6-15)$ \\
\hline \multicolumn{8}{|l|}{$>10-20$ years } \\
\hline 0 & 1.0 & 63 & 69 & 1.0 & 77 & 85 & 1.0 \\
\hline$>0-0.16$ & $1.2(0.8-1.7)$ & 56 & 76 & $1.6(1.0-2.6)$ & 35 & 32 & $0.8(0.4-1.4)$ \\
\hline$>0.16-0.40$ & $1.3(0.9-1.7)$ & 110 & 153 & $1.7(1.1-2.7)$ & 123 & 116 & $0.9(0.6-1.3)$ \\
\hline$>0.40-0.52$ & $1.2(0.9-1.7)$ & 53 & 70 & $1.7(1.0-2.8)$ & 107 & 94 & $0.8(0.5-1.2)$ \\
\hline$>0.52$ & $1.2(0.9-1.7)$ & 65 & 71 & $1.4(0.9-2.4)$ & 84 & 77 & $0.8(0.5-1.3)$ \\
\hline \multicolumn{8}{|l|}{$20+$ years } \\
\hline 0 & 1.0 & 186 & 234 & 1.0 & 52 & 42 & 1.0 \\
\hline$>0-0.19$ & $1.4(1.0-1.9)$ & 79 & 101 & $1.1(0.8-1.7)$ & 69 & 66 & $1.4(0.8-2.4)$ \\
\hline$>0.19-0.76$ & $1.5(1.1-2.0)$ & 73 & 92 & $1.1(0.7-1.7)$ & 159 & 164 & $1.6(1.0-2.6)$ \\
\hline$>0.76$ & $1.2(0.8-1.8)$ & 9 & 12 & $1.2(0.5-3.0)$ & 146 & 132 & $1.4(0.8-2.3)$ \\
\hline
\end{tabular}

Adjusted for the effects of race (Black, non-Black) and age.

* OR, odds ratio; $\mathrm{Cl}$, confidence interval. 
TABLE 4. Adjusted logistic regression odds ratios and 95 percent confidence levels for breast cancer relative to cumulative exposure to magnetic fields: Carolina Breast Cancer Study

\begin{tabular}{|c|c|c|c|c|c|c|c|c|}
\hline \multirow{2}{*}{$\begin{array}{c}\text { Exposure level } \\
\text { ( } \mu \text { T-years) }\end{array}$} & \multicolumn{2}{|c|}{ ER + , premenopausal* } & \multicolumn{2}{|c|}{ ER+, postmenopausal } & \multicolumn{2}{|c|}{ ER-, premenopausal } & \multicolumn{2}{|c|}{ ER-, postmenopausal } \\
\hline & Cases & OR $(95 \% \mathrm{Cl})^{\dagger}$ & Cases & OR $(95 \% \mathrm{Cl})$ & Cases & OR $(95 \% \mathrm{Cl})$ & Cases & OR $(95 \% \mathrm{Cl})$ \\
\hline \multicolumn{9}{|l|}{ Total exposure } \\
\hline $0-0.59$ & 82 & 1.0 & 57 & 1.0 & 82 & 1.0 & 22 & 1.0 \\
\hline$>0.59-0.90$ & 57 & $1.6(1.0-2.5)$ & 42 & $0.8(0.5-1.3)$ & 56 & $1.6(1.0-2.5)$ & 37 & $1.8(0.9-3.4)$ \\
\hline$>0.90-1.27$ & 33 & $0.8(0.5-1.4)$ & 50 & $1.1(0.7-1.8)$ & 35 & $0.9(0.5-1.5)$ & 25 & $1.6(0.8-3.1)$ \\
\hline$>1.27-2.43$ & 22 & $1.4(0.8-2.7)$ & 55 & $0.7(0.5-1.2)$ & 18 & $0.9(0.5-1.8)$ & 30 & $1.2(0.6-2.3)$ \\
\hline$>2.43$ & 11 & $1.5(0.6-3.6)$ & 44 & $1.1(0.6-1.8)$ & 6 & $0.7(0.3-2.0)$ & 15 & $1.3(0.6-2.8)$ \\
\hline \multicolumn{9}{|l|}{$0-10$ years } \\
\hline 0 & 16 & 1.0 & 96 & 1.0 & 16 & 1.0 & 35 & 1.0 \\
\hline$>0-0.12$ & 19 & $1.6(0.7-3.9)$ & 22 & $1.0(0.5-1.8)$ & 22 & $1.8(0.8-4.1)$ & 11 & $1.0(0.5-2.3)$ \\
\hline$>0.12-0.35$ & 70 & $1.3(0.6-2.5)$ & 63 & $0.8(0.5-1.3)$ & 67 & $1.0(0.5-2.1)$ & 33 & $0.9(0.5-1.5)$ \\
\hline$>0.35-0.47$ & 51 & $1.2(0.6-2.4)$ & 34 & $0.8(0.5-1.3)$ & 42 & $0.9(0.5-1.9)$ & 21 & $0.9(0.5-1.7)$ \\
\hline$>0.47$ & 49 & $1.4(0.7-2.9)$ & 33 & $0.9(0.5-1.5)$ & 50 & $1.1(0.5-2.2)$ & 29 & $1.3(0.7-2.4)$ \\
\hline \multicolumn{9}{|l|}{$>10-20$ yean } \\
\hline 0 & 28 & 1.0 & 59 & 1.0 & 35 & 1.0 & 20 & 1.0 \\
\hline$>0-0.16$ & 38 & $2.0(1.1-3.9)$ & 23 & $0.9(0.5-1.7)$ & 33 & $1.3(0.7-2.4)$ & 8 & $0.8(0.3-1.9)$ \\
\hline$>0.16-0.40$ & 73 & $2.0(1.1-3.6)$ & 62 & $0.7(0.5-1.1)$ & 66 & $1.5(0.9-2.6)$ & 45 & $1.3(0.7-2.5)$ \\
\hline$>0.40-0.52$ & 28 & $1.6(0.8-3.2)$ & 58 & $0.8(0.5-1.2)$ & 35 & $1.8(0.9-3.4)$ & 32 & $1.2(0.6-2.2)$ \\
\hline$>0.52$ & 38 & $2.1(1.1-4.0)$ & 46 & $0.8(0.5-1.3)$ & 28 & $1.0(0.6-2.0)$ & 24 & $1.1(0.5-2.2)$ \\
\hline \multicolumn{9}{|l|}{$20+$ years } \\
\hline 0 & 102 & 1.0 & 20 & 1.0 & 113 & 1.0 & 21 & 10 \\
\hline$>0-0.19$ & 51 & $1.3(0.8-2.0)$ & 35 & $1.4(0.7-2.7)$ & 40 & $1.0(0.6-1.6)$ & 26 & $1.3(0.6-2.6)$ \\
\hline$>0.19-0.76$ & 43 & $1.2(0.7-1.9)$ & 103 & $1.8(1.0-3.2)$ & 41 & $1.1(0.6-1.8)$ & 50 & $13(0.7-2.5)$ \\
\hline$>0.76$ & 9 & $2.1(0.8-5.9)$ & 90 & $15(0.8-2.9)$ & 3 & $0.6(0.1-2.2)$ & 32 & $1.0(0.5-2.2)$ \\
\hline
\end{tabular}

Adjusted for the effects of nace (Black, non-Black) and age.

"Numbers of premenopausal and postmenopausal controls across exposure categories are provided in Table 3, and are similar across ER strata.

OR, odds ratio; $\mathrm{Cl}$, confidence interval.

creased risk could be found. Consideration of potential confounding factors did not alter the results.

Wornen do not commonly work in electrical occupations, where elevated exposures can be established with some confidence, making it difficult to address the potential association between occupational exposure to EMFs and breast cancer among women. In our study, few women worked in "electrical occupations" or "other occupations with potential exposure" as classified in a much larger study by Loomis and coworkers (28). Duration of employment was shorter for jobs potentially involving higher levels of exposure, such as computer programming or work in industrial settings, which may reflect the entry of women in those type of occupations during relatively recent time periods. Average duration of employment was longer in the more traditional occupations among women, such as nursing and teaching. The potential for heterogeneity in levels of exposure to EMFs among nurses, however, should be noted; some may well have elevated exposures to EMFs.

Studies of female breast cancer and occupational exposure to EMFs have yielded inconsistent results $(29,30)$. Many of the studies used a broad definition of exposure based on either occupations $(25,28,31-34)$ or qualitative job-exposure matrices (35-39). Some of these studies found evidence for an increased risk with potential exposure to
EMFs $(25,28,31,35-37)$, whereas others did not $(32,33$, 38,39 ). Interestingly, the few studies incorporating quantitative exposure measurements found little to no evidence for an elevated breast cancer risk (40-42), largely consistent with the results of our study. This suggests that perhaps some aspect of jobs with potentially elevated exposure to EMFs is associated with an increased risk of breast cancer.

It has been suggested that exposure to EMFs might be important for ER + tumors in particular (18). Furthermore, the possible impact of exposure to EMFs on breast cancer risk may be more relevant to premenopausal women compared to post-menopausal women because premenopausal women are still producing high levels of estrogens (17). Several previous studies of occupational EMF exposure have evaluated the difference in risk by menopausal and es. trogen-receptor status, with equivocal results. Loomis et al. (28) observed an excess relative risk (RR) of $2.2(95 \% \mathrm{CI}=$ $1.2-4.0$ ) for perimenopausal (age 45-54 years) but not premenopausal or postmenopausal women. Coogan and colleagues (37) reported a higher risk $(R R=2.0 ; 95 \% \mathrm{Cl}=$ $1.0-3.8)$ for the most highly exposed premenopausal women based on usual occupation than for similarly exposed postmenopausal workers $(\mathrm{RR}=1.3 ; 95 \% \mathrm{Cl}=0.8$ 2.2). Recently, Band et al. (43) reported a notably increased but imprecise risk for premenopausal women with a 
usual occupation of electronic data processing equipment operator $(\mathrm{RR}=7.28 ; 90 \% \mathrm{Cl}=1.22-43.4)$. Another study found some indication of an increased risk in the highest exposure category for women below age 50 with ER+ breast cancer cells, but risk estimates were imprecise (42).

The results of our study suggest an increased risk of breast cancer among premenopausal women with ER+ breast cancer cells in relation to employment as industrial worker, an occupational category with the highest measured exposure to magnetic fields in this study population. Industrial workers, however, may have been exposed to a variety of potential occupational risk factors for breast cancer (44), such as solvents (43), and risk estimates were highly imprecise. Also, there may be non-occupational risk factors that distinguish this job group. A moderately decreased risk was observed for premenopausal women in the referent group in the past 10-20 years before diagnosis, with all exposed groups of similar risk. This finding was more pronounced among premenopausal women with ER+ status. Given that the referent group was not working at all, and the absence of dose-response gradients, it seems unlikely that exposure to EMFs played a role in the lower risk experienced by the referent group. In addition, the time period of 10-20 years between exposure and diagnosis could be considered inconsistent with the hypothesis that exposure to EMFs acts as a tumor promotor $(26,27)$, which would predict that relevant exposure to EMFs would be close in time to diagnosis. Exposure levels experienced in this study population are considerably lower than those encountered by electric utility workers (45), and may well have been too low to detect moderately increased breast cancer risks if any truly exist.

The results of this study must be interpreted with recognition of the limitations of use of reported longest and second-longest held job, and broad occupational categories to estimate exposure to EMFs over decades of work experience. First, the use of two longest held jobs may have yielded incomplete information on employment history; however, the average total duration of employment in our study is almost 20 years, which is somewhat greater than the average duration of employment observed in large United States cohorts of electric utility workers $(46,47)$. Secondly, recall bias in reporting employment should be considered. Nonetheless, study participants were not aware of the hypothesis under study, and reported jobs were categorized into six a priori occupational categories to estimate cumulative indices of exposure. It seems unlikely that recall bias occurred in a sufficient degree to be a major source of error in exposure assessment.

Next, the a priori occupational categories used in this study were not good predictors of exposure to magnetic fields (24). Diversity actoss multiple work environments and job tasks was not taken into account, thereby explaining only a small proportion of variability in exposure (48).
A wide variety of jobs and industries were collapsed into broad occupational categories, which may have resulted in substantial exposure misclassification. In addition, the number of exposure measurements in some occupational categories was small, thereby resulting in imprecise measures of exposure intensity. Nevertheless, two-way nested random-effects analysis of the exposure measurement data showed that the between-group variability was substantially greater than the within-group variability $(24)$, thereby indicating distinct EMF exposure levels across the six occupational categories.

Finally, the component of EMFs that may be relevant to biological effects rernains uncertain $(49,50)$. Current techniques for EMF exposure assesstnent, which focus on timeweighted average magnetic fields, are subject to error as alternative indices of electric and magnetic fields may be equally or more important in the etiology of cancer and other potential health effects $(51,52)$.

This study was supported by the Specialised Program of Research Excel. lence in Breast Cancer, NIH/NCI P50-CA58223, and the Environment and Breast Cancer Prognam, R21-CA66201. We thank Dr. Louis Wijnberg for providing information about the exposure assessment. Also, we acknowledge the substantial contribution of the study staff and the generons support of study participants, physicians, numor registrars, medical recorts and pathology staff, and administratos at purticipating North Carolina hospitals. This work was conducted at the Department of Epide. miology, School of Public Health, The University of North Carolina at Chapel Hill, Chapel Hill, NC.

\section{REFERENCES}

1. Parkin DM, Pisani P, Feriay J. Estimates of the worldwide incidence of 25 major cancers in 1990. Int J Cancer, 1999;80:827-841.

2. Ruddon RW. Cancer Biology (3rd ed.). New York: Oxford University Press; 1995.

3. Stevens RG. Electric power use and breast cancer: A hypothesis. Am ] Epidemiol. 1987; 125:556-561.

4. Stevena RG, Davis S. The melatonin hypothesis: Electric power and breast cancer. Environ Healch Perspect. 1996;104(suppl 1):135-140

5. Blask DE. Systemic, cellular, and molecular aspects of melatonin action on experimental breast carcinogenesis. In: Stevens RG, Wilson BW, Anderson LE (eds.). The melatonin hypothesis: Breast cancer and use of electric power. Columbus, OH: Battelle Press; 1997:189-230.

6. Burch JB, Reif JS, Noonan CW, Yost MG. Melatonin metabolite lev. els in workers exposed to $60-\mathrm{H}$ m magnetic fields: Work in substations and with 3-phase conductors. J Occup Environ Med. 2000:42:136142.

7. Burch JB, Reif JS, Yost MG, Keefe T], Pitrat CA. Nocturnal excretion of a urinary melatonin metabolite among electric urility workers. Scand J Work Environ Health. 1998;24:183-189.

8. Pfluger DH, Minder CE. Effects of exposure to $16.7 \mathrm{~Hz}$ magnetic fields on urinary 6 -hydroxymelatonin sulfate excretion of Swiss railway workers. J Pineal Res. 1996;21:91-100.

9. Wilson BW, Wright CW, Morris JE, Buschborn RL, Brown DP, Millet $\mathrm{DL}$, et al. Evidence fot an effect of ELF electromagnetic fields on human pineal gland function. J Pineal Res. 1990,9:259-269.

10. Karasek M, Woldanska-Okonska M, Crernicki j, Zylinska K, Swietoslawski J. Chronic exposure to $2.9 \mathrm{mT}, 40 \mathrm{~Hz}$ magnetic field reduces melatonin concentrations in humans. J Pineal Res. 1998;25:240-244. 
11. Juutilainen J, Stevens RG, Anderson LE, Hansen NH, Kilpelainen M, Kumlin T, et al. Noctumal 6 -bydroxymelatonin sulfate excretion in female worken exposed to magnetic fields. J Pineal Res. 2000;28:97-104.

12. Prato FS, Ossenkopp KP, Kavaliers M, Ulsik P, Nicholson RL, Drost $D$, et al. Effects of exposure to magnetic resonance imaging on nocturnal serum melatonin and other hormone levels in adult males: Preliminary findings. J Bioelectricity. 1989;7:169-180.

13. Schiffman JS, Lasch HM, Rollag MD, Flanders AE, Brainard GC, Burk DL. Effect of magnetic resonance imagin on the normal human pineal body. Measurement of plasma melatonin levels. J Magn Reson Imagin. 1994:4:7-11.

14. Graham C, Cook MR, Riffle DW, Gerkovich MM, Cohen HD. Nocturnal melatonin levels in human volunteers exposed to $60 \mathrm{~Hz}$ mag. netic fields. Bioelectromagnetics. 1996;17:263-273.

15. Graham C, Cook MR, Riffle DW. Hurnan melatonin during continuous magnetic field exposure. Bioelectromagnetics. 1997:18:166-171.

16. Selmaoui B, Lambrowo J, Touitou Y. Magnetic fields and pineal function in humans: evaluation of noctumal acute exposure to extremely low frequency magnetic fields on serum melatonin and urinary 6-sulfatoxymelatonin circadian thythms. Life Sci. 1996;58:1539-1549.

17. Vena JE, Freudenheim JL, Marshall JR, Laughlin R, Swanson M, Graham S. Risk of premenopausal breast cancer and use of electric blankets. Am J Epidemiol. 1994;140:974-979.

18. Stevens RG. Re: Risk of premenopausal breast cancer and use of electric blankets. Am J Epiderniol. 1995;142:446.

19. Newman B, Moorman PG, Millikan R, Quqish BF, Gerades J, Aldrich TE, et al. The Carolina Breast Cancer Study: Integrating populationbased epidemiology and molecular biologry. Breast Cancer Research Treat. 1995:35:51-60.

20. Millikan RC, Pittman GS, Newman B, Tse C, Selmin O, Rockhill B, et al. Cigarette smoking, $N$-acetyltransferases 1 and 2 , and breast cancer risk. Cancer Epidemiol Biomark Prev. 1998;7:371-378.

21. Weinberg $C R$, Wacholder $S$. The design and analysis of case-control studies with biased sampling. Biometrics. 1990;46:963-975.

22. Weinberg CR, Sandler DP. Randomised recruitment in case-control studies. Am J Epidemiol. 1991;134:421-432.

23. Moorman PG, Newman B, Millikan RC, Tse C), Sandler DP. Participation rates in a case-control study: The impact of age, race, and nace of interviewer. Ann Epidemiol. 1999;9:188-195.

24. MoCurdy AL, Wijnberg L, Savitz DA, Nylander-French LA. Exposure to $60-\mathrm{Hz}$ magnetic fields among working women and homemak. ers. Ann Occup Hyg. in press.

25. Dosemed M, Blait A. Occupational cancer mortality among women employed in the telephone industry. J Occup Med. 1994:36:1204-1209.

26. Floderus B, Persson T, Stenlund C, Wennberg A, Ot A, Knave B. Oocupational exposure to electromagnetic fields in relation to leuke. mia and brain tumoss: A case-control study in Sweden. Cancer Causes Control. 1993:4:465-476.

27. McCann J, Kavet R, Rafferty CN. Assessing the potential carcinogenic activity of magnetic fields using animal models. Environ Health Perspect. 2000;108(suppl 1):79-100.

28. Loomis DP, Savitz DA, Ananth CV. Breast cancer mortality among female electrical workers in the United States ] Natl Cancer Inst. 1994:86:921-925.

29. Caplan LS, Schoenfeld ER, OLeary ES, Leske MC. Breast cancer and electromagnetic fields-A review. Ann Epidemiol. 2000;10:31-44.

30. Brainard GC, Kavet $R$, Kheifets $L$. The relationship between electromagnetic field and light exposures to melatonin and beeast cancer risk: A review of relevant literature.J Pineal Res. 1999;26:65-100.

31. Pollan M, Gustavsson P. High-riak occupations for breast cancer in the Swedish fernale working population. Am J Public Healch. $1999 ; 89-875-881$.

32. Kelsh MA, Saht JD. Mottality among a cohort of electric utility workers, 1960-1991. Am J lnd Med. 1997;31:534-544.
33. Fear NT, Rornan E, Carpenter LM, Newton R, Bull D. Cancer in electrical worken: An analysis of cancer registrations in England, 198187. Br J Cancet. 1996; 73:935-939.

34. Vagero $D$, Olin $R$. Incidence of cancer in the electronias industry: Uking the new Swredish Cancer Environment Registry as screening instrument. Bc J lnd Med. 1983;40:186-192.

35. Centor KP, Dosemeci M, Brinton LA, Stewurt PA. Re Breast cancer mortality among fermale electrical workens in the United States. J Natl Cancer Inst. 1995;87:227-228.

36. Coogan PF, Clapp RW, Newcomb PA, Wenal TB, Bogdan G, Mittendorf $R$, et al. Occupational exposure to 60-Hert magnetic fields and risk of breast cancer in women. Epidemiology, 1996;7:459-464.

37. Tynes T, Hannevik M, Andersen A, Visenes Al, Haldorsen T. Incidence of breast cancer in Norwegian female radio and telegraph operators. Cancer Causes Control. 1996;7:197-204.

38. Petralia SA, Chow W-H, Mclaugtin J, Jin F, Gao Y-T, Dosemeci M. Occupational risk factors for breast cancer among women in Shang. hai. Am J lnd Med. 1998;34:477-483.

39. Coogan PF, Aschengrau A. Exposure to power frequency magnetic fields and risk of breast cancer in the Upper Cape Code Incidence Stucty. Arch Environ Health. 1998:53:359-367.

40. Guenel P, Rasmark P, Andersen JB, Lynge E. Incidence of cancer in persons with occupational exposure to electromagnetic fields in Des. mark. Br J Ind Med. 1993;50:758-764.

41. Johansen $C_{2}$ Olsen JH. Risk of cancer among Danish utility workers a nationwide cohort study. Am J Epidemiol. 1998;147:548-555.

42. Forssen UM, Feychting M, Rutqvist LE, Floderus B, Ahlbom A. Occupational and residential magnetic field exposure and breast cancer in females. Epidemiology. 2000;11:24-29.

43. Band PR, Lo ND, Fang R, Deschamps M, Gallagher RP, Yang P. Identification of occuparional cancer risks in British Columbia: $A$ population-based case-control study of 995 incident breast cancer cases by menopausal status, controlling for confounding factors. J Occup Environ Med. 2000;42:284-310.

44. Welp EA, Weiderpass E, Boffetta P, Vainio H, Vasama-Neuvonen $K$, Pectalia S, et al. Environmental risk factors of breast cancer. Scan J Work Environ Health. 1998;24:3-7.

45. Savitz DA, Loomis DP. Magnetic field exposure in relation to leukemia and brain cancer mortality among electric utility workess. Am J Epidemiol. 1995;141:123-134.

46. Van Wijngarden E, Savitz DA, Klecknet RC, Mihlan G, NylanderFrench LA, Dufort V, et al. Refinements in magnetic field exposure ussignment for a case-cohort study of electrical utility workers. Ann Occup Hyg. 1999; 43;7:485-92.

47. Kelsh MA, Sahl JD. Mortality among a cohort of electric utility worken, 1960-1991. Am J ind Med. 1997;31:534-544.

48. Kelah MA, Kheifes L, Smith R. The impact of work environment, utility, and sampling design on occupational magnetic field exposure summaries. Am Ind Hyg Assoc J. 2000;61:174-182.

49. Portier CJ, Wolfe MS, eds. Assessment of health effects from exposure to power line frequency electric and magnetic fields: Working group report (NIH Publ No 98-3981). Research Triangle Park, NC: National Institute of Environmental Health Sciences; 1998.

50. Valberg PA. Electric and magnetic fields (EMF): What do we know about the health effects? Int Arch Occup Environ Health $1996 ; 68: 448-454$.

51. Villeneuve PJ, Agnew DA, Mitler AB, Corey PN. Non-Hodgkin's lymphoma among electric utility workers in Ontario: The evaluation of alternace indices of exposure to $60 \mathrm{~Hz}$ electric and magnetic fields. Occup Environ Med. 2000;57:249-257.

52. Villeneuve PJ, Agnew DA, Miller AB, Corey PN, Purdham JT. Levkemia in electric utility workers: The evaluation of alternative indices of exposure to $60 \mathrm{~Hz}$ electric and magnetic fields. Am J Ind Med. 2000;37:607-617. 